\title{
Giant Plexiform Neurofibroma of the Perineum and Pelvic Cavity Manifesting as Segmental Neurofibromatosis
}

\author{
Myeong Jin Park, Gi Hyun Seong, Minkee Park, Mi Soo Choi, Seung Phil Hong, Byung Cheol Park, \\ Myung Hwa Kim
}

Department of Dermatology, Dankook University College of Medicine, Cheonan, Korea

Segmental neurofibromatosis $(\mathrm{SN})$ is rare form of neurofibromatosis characterized that cutaneous or neural changes are limited to one region of the body. SN present neurofibroma and less frequently, café au lait macules (CALMs) on usually unilateral or rarely bilateral of the body region. $\mathrm{SN}$ seems to have fewer systemic complications than neurofibromatosis type I or II, except patients with plexiform neurofibromas (PNFs). PNFs are rare benign peripheral nerve sheath tumors which arise from single or multiple nerves. PNFs can easily become aggressive growth particularly during puberty or pregnancy and leading to disfigurement and functional impairment. Also, PNFs can transform to malignant peripheral nerve sheath tumor, higher rate than classic neurofibroma. So, it is important to decide appropriate treatment modalities and time to intervention. (Ann Dermatol 31(3) $331 \sim 334,2019$ )

\section{-Keywords-}

Cafe-au lait spot, Pelvis, Plexiform neurofibroma, Segmental neurofibromatosis

Received October 20, 2017, Revised March 23, 2018, Accepted for publication June 8, 2018

Corresponding author: Myung Hwa Kim, Department of Dermatology, Dankook University Hospital, 201 Manghyang-ro, Dongnam-gu, Cheonan 31116, Korea. Tel: 82-41-550-6485, Fax: 82-41-552-7541, E-mail: ivymyung@ hanmail.net

ORCID: https://orcid.org/0000-0002-9072-201X

This is an Open Access article distributed under the terms of the Creative Commons Attribution Non-Commercial License (http://creativecommons. org/licenses/by-nc/4.0) which permits unrestricted non-commercial use, distribution, and reproduction in any medium, provided the original work is properly cited.

Copyright $\odot$ The Korean Dermatological Association and The Korean Society for Investigative Dermatology

\section{INTRODUCTION}

Segmental neurofibromatosis (SN) or type $\mathrm{V}$ neurofibromatosis (NF) is rare form of NF. Skin findings such as neurofibromas, café au lait macules (CALMs) or skin fold freckles are restricted to certain area. Although NF is one of the most common inherited diseases (incidence-1/3,000 births), SN has 10 to 20 times lower incidence than NF. Plexiform neurofibromas (PNFs) are rare benign peripheral nerve sheath tumors as bulging and deforming masses involving also connective tissue and skin folds. PNFs consisted of a proliferation of all elements of the nerve resulting in an irregularly thickened, distorted tortuous structure. PNFs rarely grow to be larger than $5 \mathrm{~cm}$, but neurofibroma can become giant lesions ${ }^{1}$. Giant PNF may progress to large invasive lesion with functional disability from 'mass effect' and disfigurement ${ }^{2}$. Furthermore, PNFs can transform to malignant peripheral nerve sheath tumor (MPNST), higher rate than classic neurofibroma. Giant PNF is difficult to manage surgically, as they are extensively infiltrative and highly vascularized.

We report a rare case of a 7-year-old girl who presented with giant PNF of perineum and pelvic cavity and CALMs manifesting as $\mathrm{SN}$.

\section{CASE REPORT}

A 7-year-old girl presented with asymptomatic skin colored papules and nodules that bound together on the left labium major and left perineal area. And there were rimpled labium major and more than $5 \mathrm{~mm}$ sized 5 CALMs overlying skin of perineal lesions (Fig. 1A). We received the patient's consent form about publishing all photographic materials.

The papules and nodules were realized as they rapidly in- 

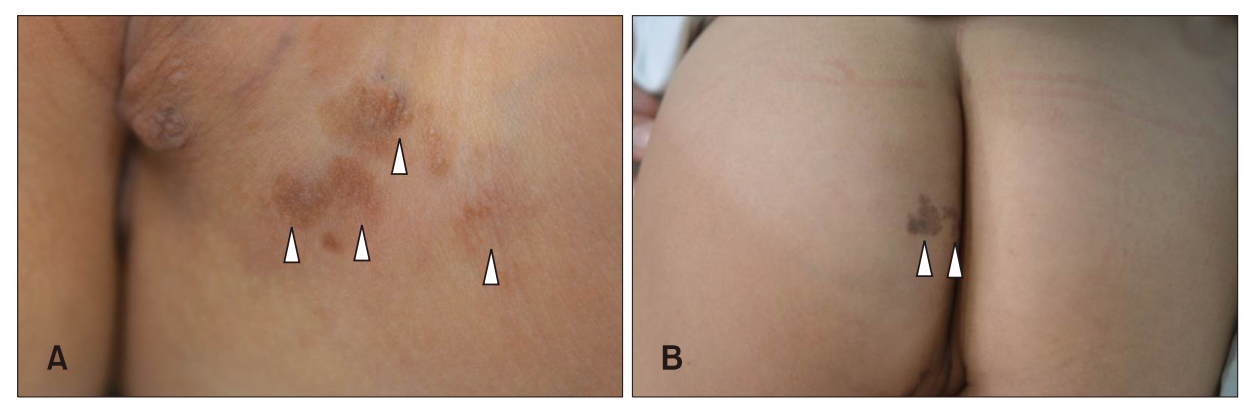

Fig. 1. (A) Asymptomatic skin colored grouped papule and nodules of the left vulva with café au lait macules (CALMs) (arrowheads). (B) CALMs (arrowheads) are located on left buttock which is bigger than right side.

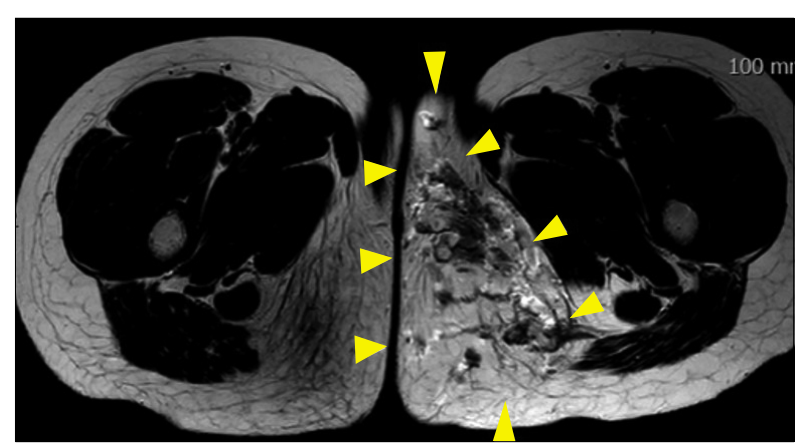

Fig. 2. On magnetic resonance imaging, it showed extensive multifocal conglomerated enhancing nodular lesion in pelvic cavity (yellow arrowheads).

creased in size over a period of one month. The CALMs were present at the birth. Left buttock is bigger than right side leaning the midline to right side (Fig. 1B). On physical examination, the perineal nodular lesions were felt as like a bag of worms. She has no axillary freckle. She had no other significant medical history or notable family history. On magnetic resonance imaging, it showed extensive multifocal conglomerated enhancing nodular lesion in both labium major, vestibular fossa, obturator internus, ischiocavernosus, urethral orifice, ischioanal fossa extending to left gluteal muscle, external anal sphincter and soft tissue in left buttock with atrophic change of left gluteus maximus (Fig. 2).

Skin biopsy were taken by skin colored nodule and CALM on vulva. In microscopic examination, the tumor was intraneural without an extraneural component. Each component of the plexus was confined by a thickened perineurium and situated at various directions with tortuous appearance (Fig. 3A). Schwann cell fascicles of the preexisting nerve were arranged along the long axis of the nerve and the endoneurial space was widened and mucinous. In it, distinctive, rounded cells (endoneurial mucocytes) were loosely spaced (Fig. 3B). Tumor cells showed positive S-100 protein immunoreactivity (Fig. 3C).

Pathologic diagnosis of plexiform intraneural neurofibroma, mucinous endoneurial type was made. The histo- pathologic differential diagnosis of PNFs includes plexiform schwannoma, intraneural plexiform neuroma. Plexiform schwannoma is intraneural and composed predominantly of Antoni A tissue. It does not show axons in the tumor mass but occasionally in the capsule. Intraneural plexiform neuroma is intraneural tumor composed of nodules and broad cords. Intraneurally broad fascicles of axons and Schwann cells are interlaced in a scanty, clear matrix. Based on these characteristic clinical findings and histopathologic features, the patient was diagnosed with $\mathrm{SN}$ with plexiform intraneural neurofibroma mucinous endoneurial type.

We recommended surgery because the huge mass could result in gastrointestinal and genitourinary complications and transform to malignant tumor. Her parents agreed with our opinion and transferred to another hospital for surgery. She underwent partial resection about the pelvic mass and conducted gene analysis in blood and tissue from removed mass. And gene mutation was detected in the tissue from operation, but not found in blood.

\section{DISCUSSION}

SN is most commonly arose as neurofibromas with or without CALMs and skin fold freckling in cervical or thoracic distribution. The age of onset varied from birth to 83 years, the mean age of onset was 28 years $^{3}$. SN is thought to be non-inherited disorder contrast to NF type I or II, because most patients have no family history of NF. Also, disease associated systemic complication such as ophthalmologic or neurologic complication is not common in $\mathrm{SN}$, except in case of PNFs. Malignancies related with $\mathrm{SN}$ is MPNST, malignant melanoma, breast cancer and Hodgkin lymphoma. The most common malignancies are MPNST and malignant melanoma ${ }^{4}$.

Most PNFs are present at birth, often stable for several years of life. PNFs occurred on mainly face, neck and inguinal region. PNFs occur rarely in genital tract such as uterus, vulva et al. Vulval neurofibroma occupies about $5 \%$ of all benign vulvar lesions ${ }^{5,6}$. Wehmeijer et al. ${ }^{7}$ pre- 

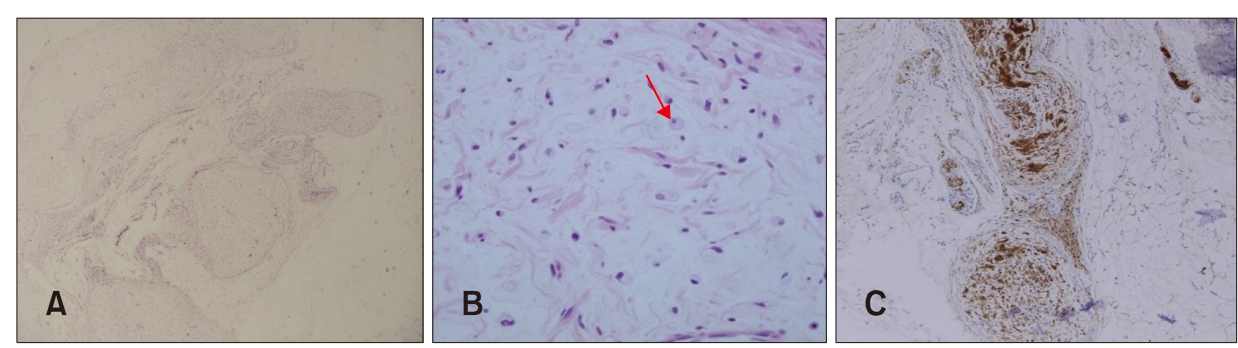

Fig. 3. (A) Well defined nodules are surrounded with perineurium and situated at various directions with tortuous appearance (H\&E, $\times 40$ ). (B) Round cells (endoneurial mucocyte) are loosely spaced (H\&E, $\times 400$, red arrow). (C) Positivity in S-100 protein immunoreactivity $(\mathrm{S}-100, \times 100)$.

Table 1. Review of the literature on segmental neurofibromatosis with plexiform neurofibroma

\begin{tabular}{llllll}
\hline \multicolumn{1}{c}{ First author } & Year & Sex, age $(\mathrm{yr})$ & \multicolumn{1}{c}{ Tumor site, size $(\mathrm{cm})$} & \multicolumn{1}{c}{ Treatment } & Complication \\
\hline Scott & 1966 & Female/27 & Scalp, $12.5 \times 9 \times 8$ & Gross total resection & Not detected \\
Wacuta & 1988 & Male/19 & Scalp, $26 \times 19$ & Gross total resection & Not detected \\
Kurimoto & 2008 & Female/34 & Scalp and neck, $>10 \mathrm{~cm}^{3}$ & Not operated & - \\
Dadlani & 2013 & Male/14 & Scalp, $12 \times 12 \times 10$ & Subtotal resection & Not detected \\
Vivek & 2016 & Male/5 & Scalp, $10 \times 10 \times 5$ & Gross total resection & Not detected \\
Our case & 2019 & Female/7 & Leftpelvic cavity, $12 \times 12$ & Partial resection & Not detected \\
\hline
\end{tabular}

sented a case of 18 years old girl with PNF of the labia minora and clitoral hood in 2015. PNFs rarely grow to be larger than $5 \mathrm{~cm}$, however neurofibroma can increase in size continuously and become giant lesions, although giant neurofibroma is a poorly defined term to describe a neurofibroma that has grown to a significant but undefined size. PNFs can easily become aggressive growth particularly during puberty or pregnancy and may lead to disfigurement and functional impairment. Furthermore, PNFs can be possible to change into MPNSTs, which occur in approximately $5 \%$ of patients ${ }^{8}$.

The histology of neurofibroma is classified into four types. Cutaneous extraneural variants, cutaneous or deep circumscribed intraneural variants, plexiform variants, deep diffuse extraneural variants belong to group of histological patterns. Above all, the intraneural neurofibroma is rare. The treatment of PNFs is not well defined. Surgery is only access to improve cosmetic problem or to prevent loss of function. But, Surgery is limited because the tumor is highly infiltrative character and tumor regrowth is common. So, it is important to decide appropriate time and extent of resection. Needle et al investigated that prognostic signs in the surgical management of 168 PNFs from 1974 to 1994. They concluded that prognostic significances age, location, extent of resection. They analyzed that the overall freedom from progression was 54\%. Children $<10$ years old had a higher progression rate after first procedure than $>10$ years old $(60.2 \%$ vs. $31.2 \%)$. Tumor in the extremities is better than tumor in head/neck/face. And also, complete tumor excision is lower progression rate than sub-total excision $(20.0 \% \text { vs. } 39.5 \%)^{9}$. In reviewing the
English literature, our case is the first case report that SN with PNF in the pelvic cavity. Table 1 shows the summary of 6 cases about SN with PNF including ours.

Finally, Riccardi's classification scheme defines segmental NF as unilateral, localized, cutaneous lesion in patients without a family history of NF. Even if the patient meets the definition by Ricarrdi, in time he may develop lesions systemically or in a distant site, and the disease would have to be reclassified as a different type of NF or as a different subgroup of segmental NF. In this perspective, the clinical diagnosis of segmental NF is experimental, and more intensive initial evaluation as well as regular follow up examinations should be considered ${ }^{10}$.

We presented a rare case of giant PNF of the pelvic cavity manifesting as $\mathrm{SN}$. Because $\mathrm{SN}$ is rare form of $\mathrm{NF}$, it is important to remember the characteristics of the $\mathrm{SN}$ not to miss diagnosis it as clinically and histologically. Also, when we experience the mass on urogenital area, radiologic imaging can be helpful to figure out the mass character like size, nature.

\section{CONFLICTS OF INTEREST}

The authors have nothing to disclose.

\section{ORCID}

Myeong Jin Park, https://orcid.org/0000-0002-5160-7932 Gi Hyun Seong, https://orcid.org/0000-0002-8425-837X Minkee Park, https://orcid.org/0000-0002-7635-7706 Mi Soo Choi, https://orcid.org/0000-0002-5040-3102 
Seung Phil Hong, https://orcid.org/0000-0002-0684-498X

Byung Cheol Park, https://orcid.org/0000-0002-5449-8313

Myung Hwa Kim, https://orcid.org/0000-0002-9072-201X

\section{REFERENCES}

1. Vélez R, Barrera-Ochoa S, Barastegui D, Pérez-Lafuente $M$, Romagosa C, Pérez M. Multidisciplinary management of a giant plexiform neurofibroma by double sequential preoperative embolization and surgical resection. Case Rep Neurol Med 2013;2013:987623.

2. Power KT, Giannas J, Babar Z, McGrouther DA. Management of massive lower limb plexiform neurofibromatosis-when to intervene? Ann R Coll Surg Engl 2007;89:W3-W5.

3. Hager CM, Cohen PR, Tschen JA. Segmental neurofibromatosis: case reports and review. J Am Acad Dermatol 1997;37:864-869.

4. Dang JD, Cohen PR. Segmental neurofibromatosis and malignancy. Skinmed 2010;8:156-159.

5. Gersell DJ, Fulling $\mathrm{KH}$. Localized neurofibromatosis of the female genitourinary tract. Am J Surg Pathol 1989;13:873878.

6. Meesa IR, Junewick JJ. Pelvic plexiform neurofibroma involving the urinary bladder. Pediatr Radiol 2008;38:916.

7. Wehmeijer LM, Hage JJ, Eberz B, van Beurden M. Partially plexiform neurofibroma of the labia minora and clitoral hood-A prognostic dilemma. J Low Genit Tract Dis 2015; 19:e55-e57.

8. Korf BR. Malignancy in neurofibromatosis type 1. Oncologist 2000;5:477-485

9. Needle MN, Cnaan A, Dattilo J, Chatten J, Phillips PC, Shochat $S$, et al. Prognostic signs in the surgical management of plexiform neurofibroma: the Children's Hospital of Philadelphia experience, 1974-1994. J Pediatr 1997;131: 678-682.

10. Roth RR, Martines R, James WD. Segmental neurofibromatosis. Arch Dermatol 1987;123:917-920. 